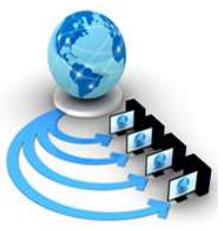

Volume 9, No. 5, September-October 2018

TECHNICAL NOTE

Available Online at www.ijarcs.info

\title{
CLOUD COMPUTING BASED JOB SCHEDULING ALGORITHM FOR CONDITION
}

\author{
R.Nirmala Devi \\ Master of Computer Application \\ C. Abdul Hakeem College Of Engineering \& Technology \\ Melvisharam-632509, Vellore District
}

\author{
M.Divya \\ Master of Computer Application \\ C. Abdul Hakeem College Of Engineering \& Technology \\ Melvisharam-632509, Vellore District
}

\begin{abstract}
Cloud computing is a type of internet based computing that provides shared computer processing resources and data to computers and other devices on demand [pay per-use model] which is changing the world around us. The reason to go for cloud computing is that it gives cost effective, flexible, mobility, secure, scalable, etc. However, the growing demand of cloud infrastructure has considerably increased the energy consumption of data centers, that has become a critical issue and thereby it increased the emission of carbon dioxide (co2) which is not environmentally friendly. To overcome this issue the technique called Green cloud computing appears that can not only save energy, but also reduce operational cost consumption is reduced in data centers by scheduling the job using priority algorithm at the rate of Power Usage Effectiveness [PUE] called PP Scheduling Algorithm. Power usage efficiency (PUE) is a metric used to determine the energy efficiency of a data center. Before the job is allocated to the data center, PUE rate for each data center is calculated and the data center with the efficient or average PUE rate is chosen for the job allocation in order to reduce the power consumption.
\end{abstract}

Keywords: cloud computing, job scheduling, energy consumption, energy saving, data centre.

\section{INTRODUCTION}

Clients can store, access and offer any measure of data in cloud. The distributed computing pattern sounds undefined; however it's not all that fluffy when you see the offer from the viewpoint of IT experts. This innovation can accomplish correspondence, stockpiling, preparing, superior, facilitating and benefits on interest to cloud client. The developing of social applications and e-business need to build the quantity of server farms. As per IDC (Universal Information Enterprise) report, the worldwide IT cloud administrations spending is evaluated to increment from $\$ 16$ billion out of 2008 to $\$ 42$ billion of every 2012, speaking to a compound yearly development rate (CAGR) of 27\% [1]. Today, a common datacenter with 1000 racks require 10 Megawatt of capacity to work, which result in higher operational expense. Along these lines, for a datacenter, the vitality cost is a huge part of its working and in advance expenses. As indicated by a report distributed by the European Association, a declines in discharge volume of $15 \%-30 \%$ is required before year 2020 to keep the worldwide temperature increment underneath 2 degree Celsius

\section{DATA CENTER}

The server farm is a substantial gathering of arranged PC server regularly utilized by association for the remote stockpiling, handling, recovering or dissemination of vast measure of information. These distributed storage supplier are in charge of keeping the information accessible, available, physical naturalsecured and running. Vitality utilize is a focal issue for server farm. Power draw for a server farm extend from $\mathrm{kW}$ for a rack of server when the outside temperature is beneath 12 or 13 degree $C$, outside air can be utilized to successfully cool warmth consumed by the cooling framework. Where on account of over 26 degree $\mathrm{C}$ it is hard to cool with the goal that we utilize power utilization viability (PUE) figuring for every datum focus.
Ordinarily server farm with 1 to 1.9 is productive, 2 to 2.5 is normal or more 2.5

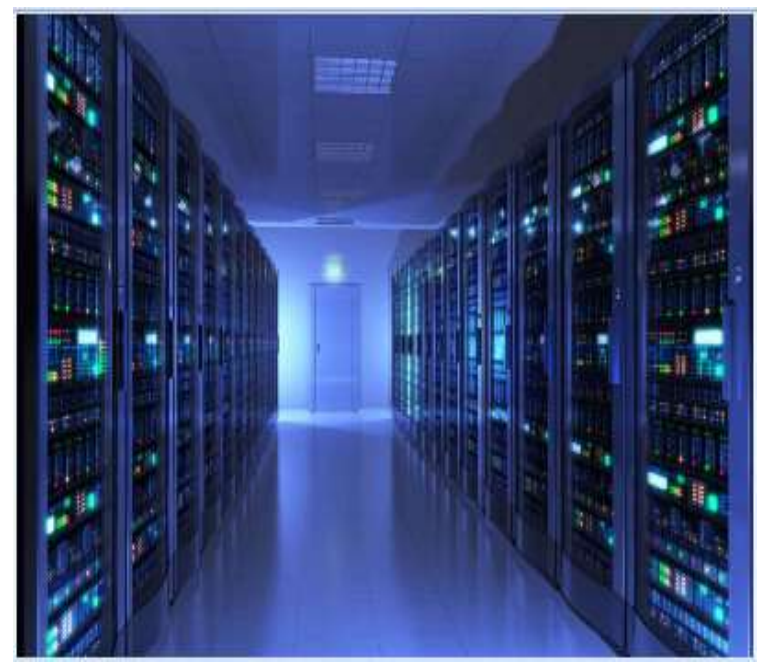

Figure 1 Data Center

\section{A. Types of Data}

The measure of electronic data (precedent: record, pictures, messages and recordings) association produces is a stunning. Putting away all the computerized information in our server farm be costly. That is the reason cloud server farm which regularly comes at a small amount of expense of putting away the data on-premises has turned out to be progressively prevalent

\section{SCHEDULING IN CLOUD}

A basic necessity in distributed computing condition is planning the current occupations to be executed with the 
given imperatives. Distributed computing is likewise about how IT is provisioned and utilized and not just about mechanical changes and furthermore the booking of server farms. The primary focus of planning is to amplify the asset use and limit preparing time of the errands. The scheduler should arrange the employments in a way where balance between enhancing the nature of administrations and in the meantime keeping up the effectiveness and decency among the occupations. An effective activity planning procedure must expect to yield less reaction time. so the execution of submitted occupations happens inside a stipulated time and at the same time there will be an event of in time asset reallocation. Thus, employments happens and more number of occupations can be submitted to the cloud by the customers which at last outcomes in quickening the business execution of the cloud framework [5].

\section{RELATED TO WORK MODEL}

The related model proposes another cross breed calculation for decrease of vitality utilization and makes range by consolidating subterranean insect state streamlining calculation (ACO) and cuckoo seek calculation. The detriment of subterranean insect state improvement has been overwhelmed by cuckoo look. The vitality devoured is figured and the change rate is contrasted with ACO calculation with deference with number of errand.

\section{B. Ant Colony Optimization}

For taking care of computational issues insect province enhancement strategy can be utilized in view of the probabilistic nature, subterranean insect state improvement is utilized to find best way through charts, in light of action of ants searching for a way among their settlement looking for nourishment source. This thought has been utilized to tackle different numerical issues; numerous issues have turned out dependent on different particular highlights of insect practices.

\section{Cuckoo Search}

Cuckoo scan is utilized for the enhancement issue, it has been seen that execution of the cuckoo look is higher than other Meta heuristic calculations. Portrayal of cuckoo seeks (CS): every last egg in the home means an answer; another arrangement is spoken to by a cuckoo egg. The fundamental inspiration of cuckoo egg is to determine the best arrangement and to supplant the arrangement, or, in other words great in the homes. Each home contains precisely one egg.

\section{Working}

Working of this algorithm is done by the initialization of pheromone, heuristic information, number of nest and random initial solution has to be done. The jobs that have to be done by the colony of ants are determined. For processing of next job, transition rule have to be applied. Construction of ant scheduling for each and every ant is carried out, that is which ant has to execute first is scheduled. Finding resources for job scheduling in cloud computing has been performed using the cuckoo search process; since cuckoo search is very easy to implement that is local search in ant colony optimization is performed using cuckoo search. Trail of pheromone is updated using a new solution and global updation is also carried out. Once local search and other non-local are performed process is terminated. [6]

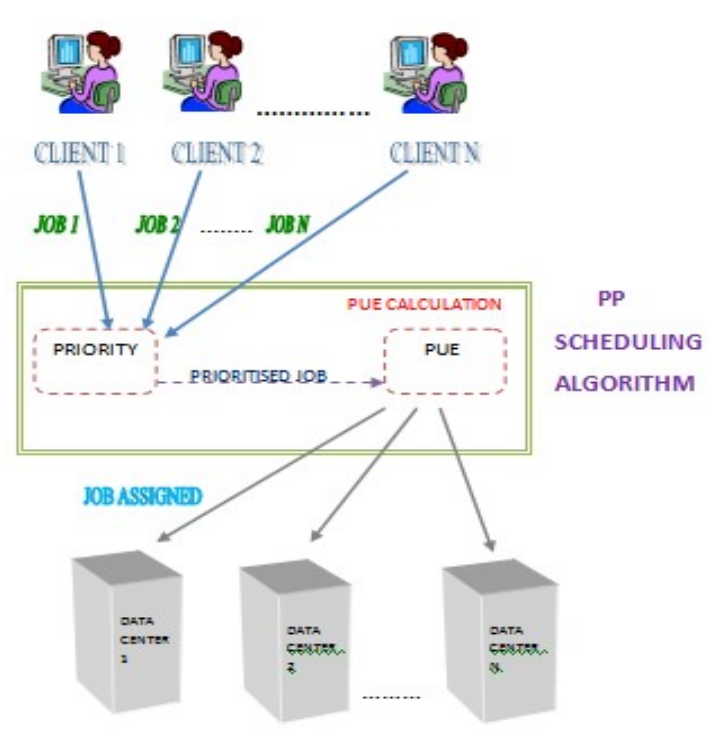

Figure 2 Architecture of Scheduling

\section{JOB SCHEDULING ALGORITHM}

This model goes for examine and explore need work planning calculations under cloud condition to give quality support of the undertakings and certification reasonableness among the occupations served. A few calculations and conventions are proposed in regards to the planning system of the distributed computing.

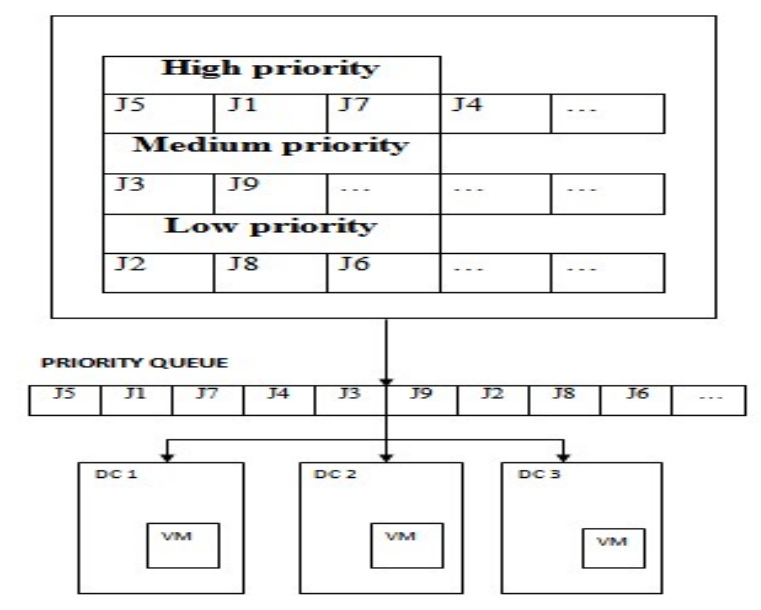

Figure 3 Job Scheduling Algorithm

It is difficult to convey the recreated work straightforwardly to this present reality since cloud administrations are layered administrations and it thinks about extra situations moreover. For instance when we are giving an administration as cloud, we have a few undertakings that have higher needs and should have been complete first and there will be some different errands 
which are characterized before and should have been performed by the planned time. These are the situations that varies the reenacted work with this present reality. To delineate reproduction in certifiable all the more adequately first partition employments into high, medium and low needs. In light of these needs the occupations are planned for the need line [7].

Be that as it may, not very many calculations are proposed to distinguish the planning component in distributed computing. A large portion of the creators consider a consistent checking district in their convention, or, in other words genuine situation. Essentially the checking area is constantly unpredictable as the mists are arbitrarily sent. So we propose a calculation to plan the employments in distributed computing. The majority of the creators consider the FCFS booking for preparing the occupations. In this condition it diminishes the assets usage and use of server. [8]

\section{POWER USAGE EFFECTIVENESS (PUE)}

Power usage efficiency (PUE) is a metric used to determine the energy efficiency of a data center. PUE is becoming a key tool used in selecting a data center.PUE is the ratio of total amount of energy used by a computer data center facility to the energy delivered to computing equipment.An ideal PUE is 1.0. Anything that is not considered a computing device in a data center (i.e. lighting, cooling, etc.) falls into the category of facility energy consumption [9].
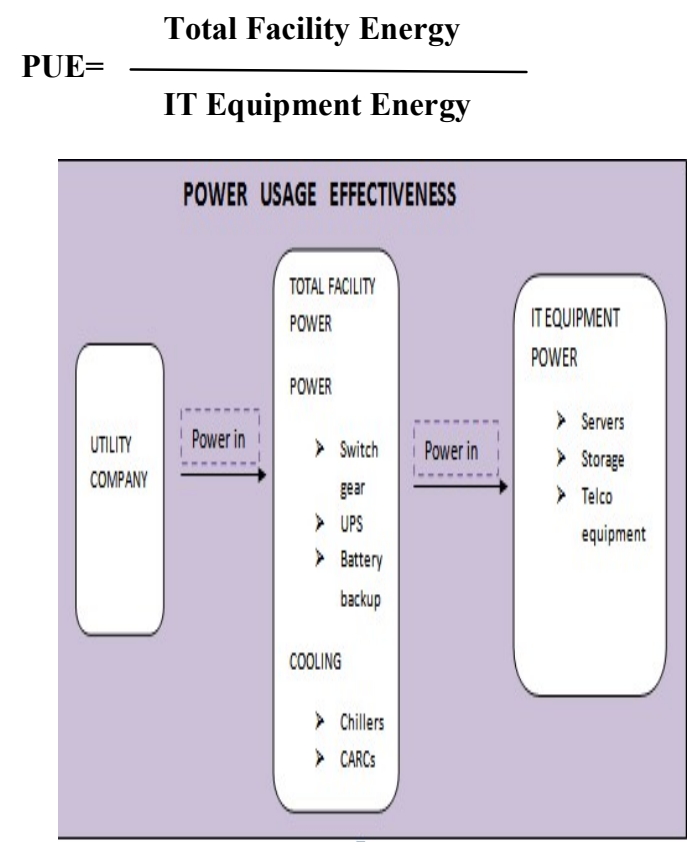

Figure 4 Power Usage Effectiveness

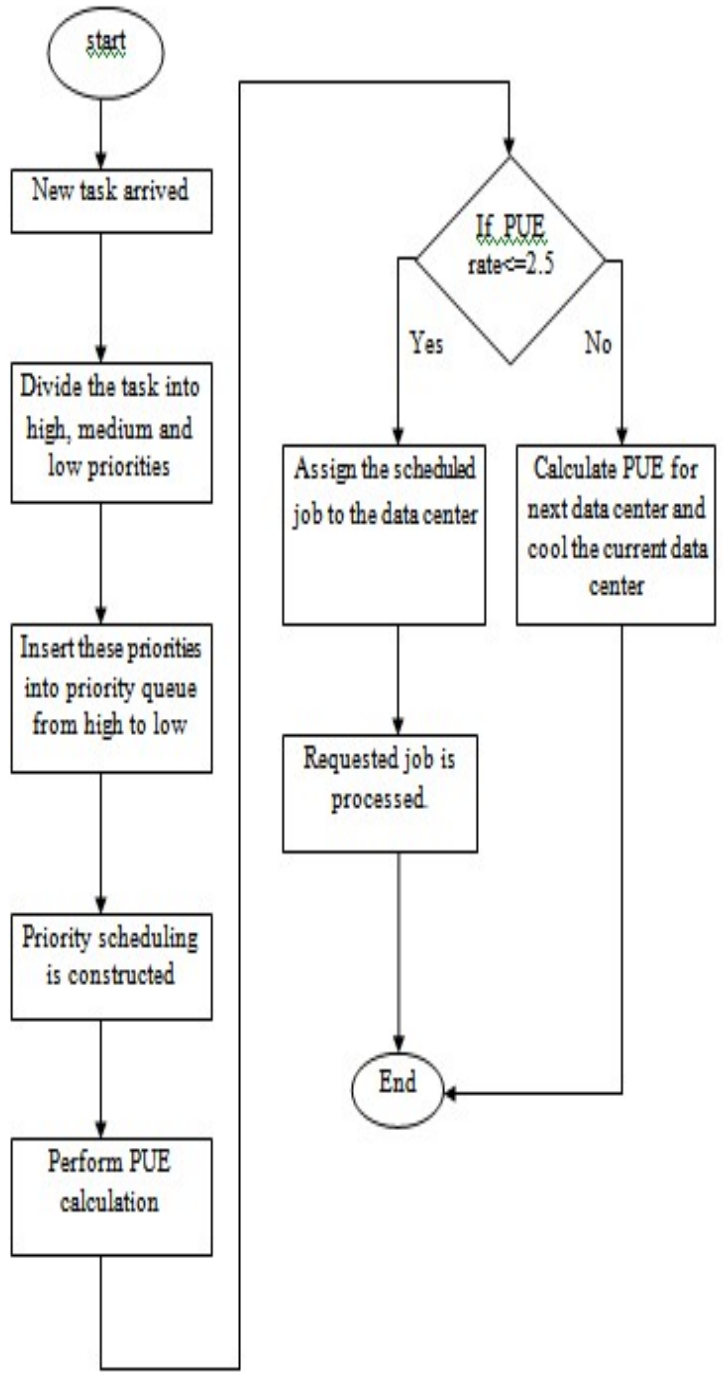

Figure 5 Flow Chart of Power Usage

\section{COMPARISON OF ALGORITHM}

Table 1

\begin{tabular}{|c|c|c|c|c|}
\hline Algorithms & Complexity & Allocation & $\begin{array}{l}\text { Waiting } \\
\text { Time }\end{array}$ & $\begin{array}{l}\text { Type of } \\
\text { system }\end{array}$ \\
\hline $\begin{array}{l}\text { FCFS } \\
\text { Algorithm }\end{array}$ & $\begin{array}{l}\text { Simplest } \\
\text { Scheduling } \\
\text { Algorithm }\end{array}$ & $\begin{array}{l}\text { CPU is } \\
\text { allocated in } \\
\text { the order in } \\
\text { which the } \\
\text { processes } \\
\text { arrive }\end{array}$ & More & $\begin{array}{l}\text { Suitable } \\
\text { for Batch } \\
\text { system. }\end{array}$ \\
\hline $\begin{array}{c}\text { SJF } \\
\text { Algorithm }\end{array}$ & $\begin{array}{l}\text { Difficult to } \\
\text { understand } \\
\text { and code }\end{array}$ & $\begin{array}{l}\text { CPU is } \\
\text { allocated to } \\
\text { the process } \\
\text { with least } \\
\text { CPU burst } \\
\text { time }\end{array}$ & $\begin{array}{l}\text { Lesser } \\
\text { than } \\
\text { FCFS }\end{array}$ & $\begin{array}{l}\text { Suitable } \\
\text { for Batch } \\
\text { system }\end{array}$ \\
\hline $\begin{array}{l}\text { Priority } \\
\text { Algorithm }\end{array}$ & $\begin{array}{l}\text { Difficult to } \\
\text { understand }\end{array}$ & $\begin{array}{l}\text { Based on } \\
\text { priority, So } \\
\text { the higher } \\
\text { priority job } \\
\text { can run } \\
\text { first. }\end{array}$ & Lesser & $\begin{array}{l}\text { Suitable } \\
\text { for both } \\
\text { Batch and } \\
\text { time } \\
\text { sharing } \\
\text { systems }\end{array}$ \\
\hline $\begin{array}{l}\text { Round } \\
\text { Robin } \\
\text { Algorithm }\end{array}$ & $\begin{array}{l}\text { Performance } \\
\text { heavily } \\
\text { depends } \\
\text { upon the size } \\
\text { of time } \\
\text { quantum }\end{array}$ & $\begin{array}{l}\text { The } \\
\text { preemption } \\
\text { take place } \\
\text { after a fixed } \\
\text { interval of } \\
\text { time }\end{array}$ & $\begin{array}{l}\text { More } \\
\text { than all }\end{array}$ & $\begin{array}{l}\text { Suitable } \\
\text { for time } \\
\text { sharing } \\
\text { system }\end{array}$ \\
\hline $\begin{array}{l}\text { Genetic } \\
\text { Algorithm }\end{array}$ & $\begin{array}{l}\text { Complexity } \\
\text { depends on } \\
\text { the task to be } \\
\text { scheduled }\end{array}$ & $\begin{array}{l}\text { This is a } \\
\text { greedy } \\
\text { algorithm } \\
\text { and pick } \\
\text { the best job } \\
\text { to allocate } \\
\text { the CPU }\end{array}$ & $\begin{array}{l}\text { Waitin } \\
\text { g time } \\
\text { is less }\end{array}$ & $\begin{array}{l}\text { It deals } \\
\text { with } \\
\text { problem } \\
\text { where the } \\
\text { search } \\
\text { space is } \\
\text { large }\end{array}$ \\
\hline
\end{tabular}




\section{ADVANTAGES OF CLOUD COMPUTING}

1. Job scheduling is global centralized - As distributed computing is a figuring model which supply the concentrated asset by the mirror administration to different appropriated applications, and this reflecting arrangement can make heterogeneous systems.

2. Each node in the cloud is independent- In distributed computing, the interior booking of each cloud hub is selfgoverning, and the schedulers in the cloud won't meddle with the planning arrangement of these hubs.

3. The set of job scheduling- The scale of resources supply from cloud provider may be limited in early stages. The size of assets supply from cloud supplier might be restricted in beginning times.

4. The set of occupation booking - Errand planning is isolated into two sections: one is utilized as a bound together asset pool planning, and fundamentally in charge of the booking of utilizations and cloud Programming interface; the other is for the brought together port asset.

\section{CONCLUSION}

In existing model, subterranean insect settlement association plans the activity and cuckoo seek picks the best $\mathrm{VM}$ and in proposed demonstrate we plan the activity utilizing need planning and best server farm is picked by utilizing PUE rate. In this paper the issue of vitality utilization in server farm is explored. PP planning calculation was proposed and it is actualized in the engineering of PP booking. With the assistance of intensity utilization adequacy (PUE), the booked activity is doled out effectively to the server farm. By this the server farm with high PUE rate are compelled to stop and permitted to cool which decreases the power utilization in the server farm which thusly controls the outflow of co2. Alongside power utilization it plan the activity inside their due date, which results in load offsetting with time proficiency.

\section{REFERENCES}

[1]. Kalange Pooja, R. "Applications of green cloud computing in energy efficiency and environmental sustainability." IOSR Journal of Computer Engineering (IOSR-JCE) (2013): 25-33.

[2] Mell, Peter, and Tim Grance. "The NIST definition of cloud computing." (2011).

[3] Maini, Raman, and Himanshu Aggarwal. "Study and comparison of various image edge detection techniques." International journal of image processing (IJIP) 3.1 (2009): 1-11

[4] Goyal, Akhil, and Navdeep S. Chahal. "Bio inspired approach for load balancing to reduce energy consumption in cloud data center." Communication, Control and Intelligent Systems (CCIS), 2015. IEEE, 2015.

[5] Sindhu S, Mukherjee S. Efficient task scheduling algorithms for cloud computing environment. InHigh Performance Architecture and Grid Computing 2011 (pp. 7983).Springer, Berlin, Heidelberg.

[6] Moganarangan N, Babukarthik RG, Bhuvaneswari S, Basha MS, Dhavachelvan P. A novel algorithm for reducing energy-consumption in cloud computing environment: Web service computing approach. Journal of King Saud University-Computer and Information Sciences. 2016 Jan 1;28(1):55-67.

[7] Xu B, Zhao C, Hu E, Hu B. Job scheduling algorithm based on Berger model in cloud environment. Advances in Engineering Software. $2011 \mathrm{Jul}$ 1;42(7):419-25.

[8] Tripathy L, Patra RR. Scheduling in cloud computing. International Journal on Cloud Computing: Services and Architecture (IJCCSA). 2014 Oct;4(5):21-7.

[9] Sharma, Tejinder, and Vijay Kumar Banga. "Efficient and enhanced algorithm in cloud computing." International Journal of Soft Computing and Engineering (IJSCE) ISSN (2013): 2231-2307.

[10] Saini T. Dr Ajay jangra "Scheduling Optimization in Cloud Computing". Int. Journal of Advanced Research in Computer Science and Software Engineering (ISSN: 2277 128X) April. 2013

[11] Huang L, Chen HS, Hu TT. Survey on Resource Allocation Policy and Job Scheduling Algorithms of Cloud Computing1.JSW. 2013 Feb 1;8(2):480-7.

[12] Bhardwaj A. Comparative Study of Scheduling Algorithms in Operating System. International Journal of Computers and Distributed Systems scheduling in the cloud computing. 